\title{
A case of pagetoid squamous cell carcinoma in situ: Bowen's disease of the glans penis requiring differentiation from extramammary Paget's disease
}

\author{
Hiroki Furukawa, Hisayoshi Imanishi, Junko Sowa-Osako, Toshiyuki Ozawa, \\ Takashi Hashimoto, Daisuke Tsuruta
}

Department of Dermatology, Osaka City University Graduate School of Medicine, Osaka, Japan

Corresponding author: Prof. Takashi Hashimoto, MD, E-mail: hashyt@gmail.com

Sir,

An 84-year-old Japanese male visited us with a six-month history of an erosive lesion involving almost the entire glans penis (Fig. la), unresponsive to topical diflucortolone valerate. The past history included only surgery for a left hip dislocation. The family history revealed no skin cancer.

All routine laboratory test results were within normal limits. MRI revealed neither subcutaneous invasion of the skin lesions (Fig. 1b) nor pelvic lymphadenopathy.

A skin biopsy revealed a thickened epidermis composed of tumor cells with disordered cell arrangement and inflammatory cell infiltration in the upper and middle dermis (Fig. lc). There was no evidence of invasion of the tumor cells into the dermis. The entire epidermis was replaced by large pagetoid cells with clear, slightly basophilic cytoplasm, and intercellular bridges were present between the clear cells (Fig. 1d).

As the differential diagnoses of the intraepithelial neoplasia on the glans penis with a cellular morphology resembling Paget's disease, which was found in our patient, we considered four diseases: primary extramammary Paget's disease (EPD) [1], secondary EPD as epidermotropism of coexisting dermal or internal malignancies in the pelvis [2], malignant melanoma in situ [3], and squamous cell carcinoma (SCC) in situ (Bowen's disease) [4]. SCC in situ (Bowen's disease) confined to non-hair bearing genital areas is also referred to as erythroplasia of Queyrat.

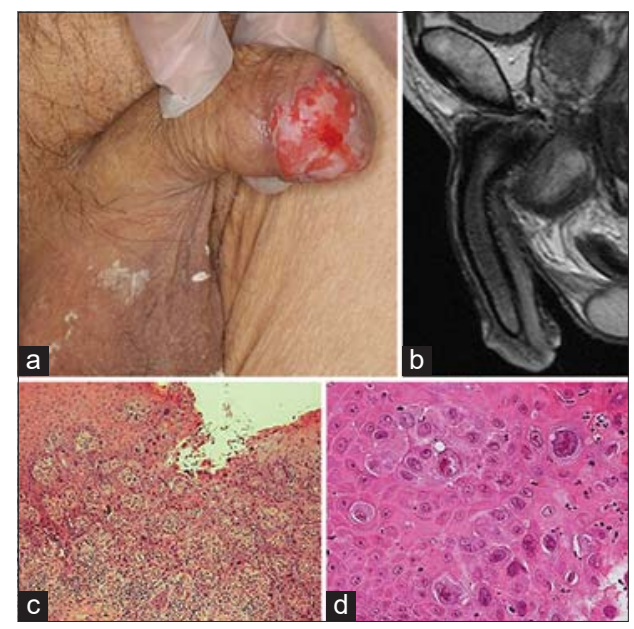

Figure 1: Clinical, MRI, and histopathological features in our case. (a) Clinical features of the lesion on the glans penis. (b) The results of MRI of the penile region. (c-d) Histopathological features under magnification: (c) $100 \times$ and (d) $400 \times$ (H\&E).

We first excluded the possibility of malignant melanoma by epithelial morphology with intercellular bridges.

For the differentiation of the other three conditions, we performed immunohistochemical studies for cytokeratin-7 (CK-7) [1], CAM5.2 [2,3], and carcinoembryonic antigen (CEA) [4] as the markers for primary EPD, CK-20 [1] as the marker for secondary EPD, CK-5/6 [2] and p 40 [5] as the markers for Bowen's disease. The tumor cells in our patient were positive for CK-5/6 and p40 (Fig. 2) and negative for CK-7, CK-20, CAM5.2, and CEA (data not shown).

The negative staining for CK-7, CAM5.2, and CEA excluded primary EPD. Although the negative staining

\footnotetext{
How to cite this article: Furukawa H, Imanishi H, Sowa-Osako J, Ozawa T, Hashimoto T, Tsuruta D. A case of pagetoid squamous cell carcinoma in situ: Bowen's disease of the glans penis requiring differentiation from extramammary Paget's disease. Our Dermatol Online. 2021;12(1):90-91.

Submission: 20.11.2020; Acceptance: 02.12.2020

DOI: 10.7241 /ourd.20211.27
} 


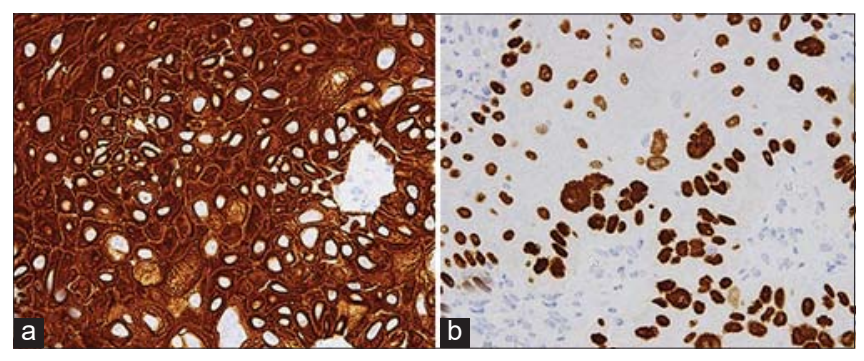

Figure 2: The results of immunohistochemical studies. (a) Staining for CK-5/6 (magnification: 400x). (b) Staining for p40 (magnification: 400x).

for CK-20 cannot completely exclude secondary EPD [1], the clearly positive staining for CK-5/6 and p40 of the tumor cells led us to the final diagnosis of pagetoid SCC in situ (Bowen's disease).

Because the lesions extended to the urethral meatus, to exclude invasion into the urethra, a urologist performed cystoscopy, which revealed no obvious neoplastic lesions in the urethra, bladder, or ureters. The corpus spongiosum and a portion of the urethra were resected according to the penile carcinoma protocol, although invasions into the dermis were not apparent. No recurrence was observed during a follow-up period of three years.

A literature survey revealed that our patient had been the seventh case of pagetoid Bowen's disease found in a genital area.

The patient had provided written informed consent for publication.

\section{Consent}

The examination of the patient was conducted according to the principles of the Declaration of Helsinki.

The authors certify that they have obtained all appropriate patient consent forms, in which the patients gave their consent for images and other clinical information to be included in the journal. The patients understand that their names and initials will not be published and due effort will be made to conceal their identity, but that anonymity cannot be guaranteed.

\section{REFERENCES}

1. Ohnishi T, Watanabe S. The use of cytokeratins 7 and 20 in the diagnosis of primary and secondary extramammary Paget's disease. Br J Dermatol. 2000;142:243-7.

2. Stefano C, Giuseppe del T, Romano M, Carmine A. Primary bilateral extramammary Paget's disease of the axillae: Another case of this strange disease. J Cutan Aesthet Surg. 2014;7:131-4.

3. Quinn AM, Sienko A, Basrawala Z, Campbell SC. Extramammary Paget disease of the scrotum with features of Bowen disease. Arch Pathol Lab Med. 2004;128:84-6.

4. Amin A, Griffith RC, Chaux A. Penile intraepithelial neoplasia with pagetoid features: report of an unusual variant mimicking Paget disease. Hum Pathol. 2014;45:889-92.

5. Gailey MP, Bellizzi AM. Immunohistochemistry for the novel markers glypican $3, \mathrm{PAX} 8$, and $\mathrm{p} 40(\Delta \mathrm{Np} 63)$ in squamous cell and urothelial carcinoma. Am J Clin Pathol. 2013;140:872-80.

Copyright by Hiroki Furukawa, et al. This is an open-access article distributed under the terms of the Creative Commons Attribution License, which permits unrestricted use, distribution, and reproduction in any medium, provided the original author and source are credited.

Source of Support: Nil, Conflict of Interest: None declared. 